\title{
Gris sobre gris
}

\author{
Antonio Navas Montilla \\ Universidad Complutense de Madrid \\ Departamento de Historia del Arte III Contemporáneo
}

Miembro del Proyecto de Investigación I+D: Sinestesias: analogías e interrelaciones entre la música, las artes y la literatura en el siglo XX. Para una cosmología de los sentidos. (ref. HAR2011-29305/Arte) anttonio.navas@gmail.com

\section{RESUMEN}

Desde sus primeras definiciones, el color gris ha sido considerado el color de la teoría y la tristeza, e incluso el "color muerto" de la pintura. Sin embargo, en ocasiones aparece anudado al cuerpo como imagen del sentido del tacto. Situados en esta contradicción, nos proponemos abordar el gris como fenómeno de gestación del arte moderno.

Palabras clave: Teoría del color; gris; tacto; sinestesia; pintura del siglo XIX.

\section{Grey on grey}

\begin{abstract}
From his beginning, the grey color has been considered the color of the theory and the sadness, and even the "dead color" of the painting. However, sometimes the grey color turns out to be knotted to the body as an image of the sense of touch. Placed in this contradiction, we propose to approach the grey as phenomenon of gestation of the modern art.
\end{abstract}

Key words: Color theory; grey; touch; synesthesia; nineteenth-century painting. 
Nadie podía presagiar que la tarde en que Charles Blanc y Paul Chenavard discutían acaloradamente acerca del color en las galerías del Palais-Royal de París, sería determinante para el cambio de rumbo de la pintura moderna. Eugène Delacroix lo anuncia "clignant les yeux", recuerda Blanc al cabo de los años, al acudir alentado a su encuentro tras escuchar al crítico sostener con rotundidad que "los grandes coloristas son aquellos que no aplican el tono local" ${ }^{1}$. Y es que si como al parecer creía Blanc, al emplear el contraste de colores puros produciendo una suerte de movilidad dinámica del color se eliminaba el tono local, que es, por cierto, el único que conserva su potencia máxima de coloración, por "colorista" podemos entender una pintura que paradójicamente reduce esa fuerza a una gama de tonos más apagados y, entonces, a una pintura de tonalidades grises. Porque tono local es, en efecto, un término esquivo que vincula el color propio de un objeto con aquel otro que éste toma localmente por efecto del claroscuro. Sin embargo, como explicaran Levesque y Watelet en la Enciclopedia, desde el siglo XVI había sido utilizado indistintamente para designar tanto el color localizado en un objeto como el que procura la atmósfera de un determinado lugar, mencionan, como paradigma, Venecia. En cierta forma, Blanc está cuestionando la ambigüedad del color que nos ocupa, para explicar a continuación el asombroso e inesperado aserto de la pintura formulado por Delacroix que veremos más adelante. De ahí, su complicidad acerca de un concepto que Delacroix empleaba a menudo en su diario para referirse al cuerpo como acontecimiento ${ }^{2}$. Desde entonces la pintura se verá en ocasiones envuelta en una nebulosa nada, como La Grande Jatte de Seurat que debate los cuerpos entre la grisalla del dibujo y la sensación atmosférica del polvo y cuyos efectos pueden seguirse a lo largo de toda la historia moderna del color.

Pero en este encuentro, el color gris parecía caracterizar a Chenavard por encima de cualquier otro, incluso de Granet, un discípulo de David a quien Delacroix recuerda haber oído decir que la pintura consistía en "poner un poco de blanco sobre negro y de negro sobre blanco"'. Algo que muestra de manera conflictiva la relación del gris con la pintura. Pues si bien, por un lado, puede llegar a destruirla, por otro, encuentra en este color su explicación última. En primer lugar, porque Chenavard era un "cerebro erizado de puntas", escribía a propósito Baudelaire, como si con esa cualidad

1 BLANC, Charles, Les artistes de mon temps, Paris, 1876, p. 23-24. "Pour moi, les grands coloristes sont ceux qui ne font pas le ton local". Blanc data el encuentro tres meses antes de la muerte de Delacroix acontecida en agosto de 1863. Siguiendo esta advertencia situaremos el incidente en el mes de mayo, y en cualquier caso en el declinar de su pintura, al "parpadear" o "entornar los ojos". Pero este gesto que Delacroix acompañaba con un paso hacia atrás cuando observaba una pintura, es seguramente, un tiempo sin tiempo. Es cerrar el ojo, negarlo, negar la vista, exigiendo por el contrario lo secreto, lo oscuro o nocturnal que esa interrupción manifiesta, y sin lo cual apenas sería posible ver.

2 Cfr., infra notas 16 y 18.; LEVESQUE, Pierre-Charles, WATELET, Claude-Henri, voz "Localite" en Encyclopédie méthodique. Beaux-Arts, T.1, Paris, 1788-1791, p.479; LAURE, Anne, Romantisme et Mélancolie. Le Journal de Delacroix, Paris, Ed. H. Champions, 1998.

3 DELACROIX, Eugène, Journal 1822-1863, "Paris, 25 janvier, 1857”, Paris, Plon, 1982, p.635. “Granet disait que la peinture consistait à mettre du blanc sur du noir et du noir sur du blanc". 
táctil el poeta sugiriese el dolor que a su juicio podría suponer un exceso de pensamiento en pintura. La de Chenavard, vista "a través de un ambiente de vapores", de grises, se encontraba en consonancia con el enigmático círculo intelectual de Lyon, cuyos postulados filosóficos engarzaban con su propósito de sugerir el intelecto desde el aleccionamiento histórico, moral o teórico con una pintura "plastique", apunta Baudelaire, mediante la cual anudar, junto a la homogeneidad del gris, las artes del disegno con lo específicamente escultórico: la expresiva cualidad táctil que Baudelaire denomina en su conjunto "El arte filosófico" proyectada por Chenavard para los muros del Panteón de París donde el pintor se había propuesto el ambicioso proyecto, interrumpido en 1851, de representar la historia de la humanidad de principio a fin, constituía, para Gautier, una clara muestra del arte moderno. Pero esa modernidad sólo se manifestaba en la medida en que el arte lograse, en palabras de Gautier, "descender del cerebro a la mano y no remontar de la mano al cerebro" como quizá cabría suponer de Delacroix, tal vez, para el poeta un efecto punzante en pintura ${ }^{5}$.

Y en segundo lugar, porque gris y tacto, precisamente anudados, pueden a menudo constituir algo inquietante que Baudelaire anunciaba en Chenavard como "un gran espíritu de decadencia [que] permanecerá como signo monstruoso de la época"6. Tal decadencia, añade, se debía a la fatalidad en que las artes manifestaban su deseo de intervenir en dominios sensoriales distintos, es decir, en el creciente interés por la sinestesia, aunque tratándose del arte filosófico de Chenavard, la decadencia articulaba imagen y pensamiento escrito. La misma idea aparece en el Diccionario de Bellas Artes de Delacroix. Este siglo, dice, está marcado por la ausencia de imaginación, pero la "décadence" contenía también la resistencia del ser humano a la fatalidad de su destino. Por eso para Baudelaire el arte filosófico se había extendido como un "color amargo" desde sus orígenes, la pintura alemana de Overbeck o Alfred Rethel, hasta la de Janmot o Vincent Brivet, pues una naturaleza reflexiva y curtida en la razón como la francesa, resultaba ser la más propicia para el asiento y desarrollo de semejante síntoma de decrepitud.

Así entendido, todo hace pensar que el gris anuncia el fin de la pintura. Pero el hecho de que contribuyese a acentuar una "decadencia fatal" en este "espíritu melancólico" de Chenavard, en palabras del crítico Théophile Silvestre, obliga a cuestionarnos cómo afectaría entonces en la pintura de Delacroix, teniendo en cuenta que a

4 BAUDELAIRE, Charles, "El arte filosófico", Salones y otros escritos sobre arte, Madrid, La Balsa de la Medusa, 1999 (1868), pp. 397-404; Cfr. SLOANE, C. Joseph, "Baudelaire, Chenavard, and 'Philosophic art"”, The journal of aesthetics \& art criticism, Vol. XIII, n 3, March, 1955, pp. 285-299. Sobre el círculo de Lyon vid., BUCHE, Joseph, L'école mystique de Lyon, 1776-1847: le grand Ampére, Ballanche, Cl.-Julien Bredin, Victor de Laprade, Blanc Saint-Bonnet, Paul Chenavard, Paris, Felix Alcan, 1935.

5 GAUTIER, Thèophile, "Le Pantheon", L'art moderne, Paris, 1856, p. 3. "Le désir du tableau pour lui-même il'a peu agité et il s'est dit que l'art devait descendre du cerveau á la main, et non remonter de la main au cerveau [...]". Conviene señalar que el programa iconográfico de Chenavard para el Panteón pudo haber seguido las indicaciones del también inconcluso Essai de palingénésie sociale (1827-1829) del místico lionés Pierre-Simon Ballanche, en cuya primera parte, "La Ville des Expiations", lugar pensado para instruir el "sentido de la vida", se describe la arquitectura de un templo esotérico con bajorrelieves de la cosmogonía del mundo, que dejo pendiente para otra ocasión.

6 BAUDELAIRE, Charles (1868), op.cit., p. 403. 
pesar de ser su más radical opositor constituía en cambio la base de su pintura. Más aún, considerando que la pintura de Delacroix, nos dice Baudelaire, no conoce la decadencia sino que sólo muestra progreso. Ahora bien, Delacroix arrastra decadencia en el progreso que sin embargo muestra, en la medida en que indica un fenómeno siempre en proceso de ser presente, resultado de ambas fuerzas en movimiento, como entre el blanco y el negro, declive y devenir. Para ello es preciso que cada elemento aparezca como un entramado de presentes articulados y operantes, tocados por lo que cada cual no es, decadencia o progreso, absolutamente. Esta exigencia de interrupción temporal les constituye como devenir irreductible generando la apertura de los sentidos. Pues bien, este fenómeno es lo moderno. La pintura de Delacroix se adentraría por tanto en un acontecimiento temporal abierto, sin dirección única, gris, entonces, hendida por los movimientos futuro y pasado, exigiendo la apertura de realidades artísticas distintas, otras: lo nuevo siempre para darse siempre de nuevo.

Mallarmé, que había evocado la "emoción gris" en las cenizas de su Igitur, advertía de algún modo esta cuestión a propósito de la pintura de Manet, al afirmar que cuando el pintor adopta el aire como medio exclusivo de la imagen, como visión, logra manifestar "aquello que vive perpetuamente pero muere en cada instante"7. De tal manera que cuando la pintura logra producir una emoción de tales características de la que solamente la sensación da testimonio, la sensación que esa intensidad manifiesta, entonces la pintura despertaría el interés de Delacroix. Antes incluso de que Taine codificara en Del'Intelligence cómo las sensaciones producen imágenes, Delacroix describía claramente este proceso, como una experiencia física de orden táctil: "Este género de emoción propio de la pintura es de algún modo tangible [...]"8 advierte. Y es la tangibilidad que posibilita el gris no sólo como presente sino en su dimensión de presencia, lo que enuncia el acontecimiento sensible en su pintura, cuyo fin es, prosigue, “amplificar [...] prolongar la sensación”. Esta tarea le corresponde a la memoria. Pero a la memoria que, como gozne, articula esa tangibilidad de la imagen. Sensación y memoria conforman la imaginación, dirá Delacroix, que a su vez funciona como generador de efectos de recuerdo. También para Baudelaire es un distintivo de modernidad, incluyéndola bajo el epígrafe "El arte mnemónico" en El pintor de la vida moderna (1864) para explicar cómo las sensaciones ocupan un lugar en la memoria.

7 MALLARMÉ, Stéphane, "Les impressionistes et Edouard Manet”(1876), AA.VV. Les écrivains devant $l$ impressionisme, Paris, Macula, 1989, p.95. Baudelaire había escrito algo muy similar sobre Delacroix al decir que "Todo lo que hay de dolor en la pasión, le apasiona". Cfr., BAUDELAIRE, Charles, "La vida y la obra de Eugène Delacroix”, op.cit., 1863, p.330. Mientras que Chenavard, asumía por su parte, según Silvestre, el papel contrario: "Notre philosophe a fondu ses lectures, ses impressions, ses souvenirs, ses contradictions en une espèce de système dont le point de départ est la négation du progres humain"; Vid., SILVESTRE, Théophile, "Chenavard, peintre", Histoire des artistes vivants, Paris, 1856, p.98.

8 DELACROIX, Eugène, op. cit.,"20 octobre 1853”, pp. 371-373. El subrayado es suyo. Además señala que no le interesa tanto la iconografía como las sensaciones que las cualidades expresivas de la forma transmiten a la imaginación, cuyo efecto define como el de un "golpeo". Por su parte, Taine, profundo admirador de Delacroix, considera que toda sensación es una "percepción externa" que produce imágenes, y que toda imagen en tanto sensación, renace intensamente a través de la memoria como un resumen sensible de esa experiencia, como una "impresión" repetida. Vid., TAINE, Hippolyte A. "Les images", De l'Intelligence, t.1, Paris, Hachette, 1892 (1871), pp.75-161. 


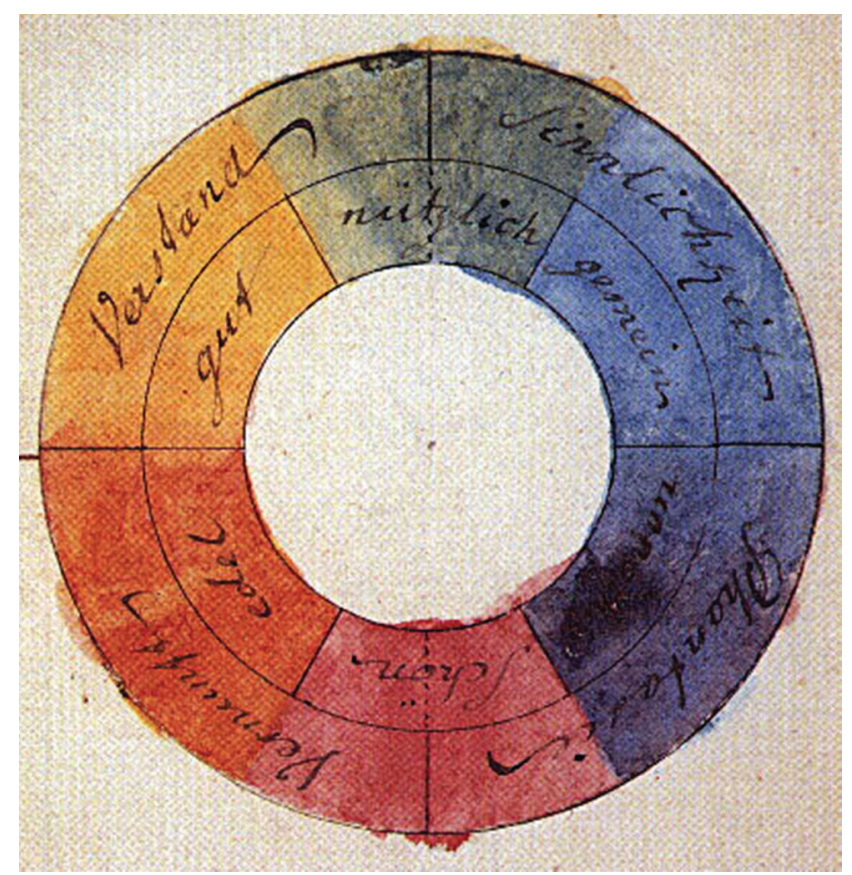

Fig. 1. Johann Wolfgang von Goethe, Círculo cromático, 1810.

Así se conformarían las imágenes, pero ¿cómo aparece lo tangible en el gris? Una respuesta posible deriva de la Teoría de los colores de Goethe (Fig.1), donde el poeta alemán había formulado el gris indistintamente como color de la teoría y, según se pensaba desde Aristóteles, como argumentación dialéctica entre los colores blanco y negro. Sin embargo, propone una tesis revolucionaria al afirmar que la suma de todos los colores no era blanco, como creía Newton, sino gris, según el convencimiento, ha escrito Javier Arnaldo, de que "los colores son sombra" conforme a la polaridad que el poeta advierte en la combinación luz-opacidad de los fenómenos naturales, formulando el gris como acontecimiento. Aquí aparece un concepto decisivo y es, según Goethe, que los colores surgen en efecto aus dem Trüben, esto es, "de lo nublado", del gris ${ }^{9}$. Esta contrariedad resulta tan precisa para algunos pintores, que en adelante se establecerá como eje interpretativo desde el que abordar la cuestión de cómo tal acontecimiento temporal, esta nada, antecede al cuerpo en pintura e incluso cómo el

9 vid., GOETHE, W. J., Zur Farbenlehre, 1810. Trad. Cast., GOETHE, W. J., Teoría de los colores, Colegio Oficial de Arquitectos Técnicos de Murcia, Valencia, 1999.; Cf. GOETHE, W. J. Fausto, [Acto I, escena IV], Obras Completas, t. I, Madrid, Aguilar, p. 383.; "Gris es toda teoría, mi caro amigo, y verde el áureo árbol de la vida". Trüben, por cierto, guarda un estrecho vínculo con el término griego $\mu \varepsilon \lambda \alpha \sigma$ que a su vez deriva en "melancolía", y en época homérica identifica los conceptos de oscuro o sombrío y, más tarde, negro, en referencia a la profundidad del mar o del vino, pero también a otros aspectos vinculados al gris como son la ceniza, el humo, las nubes, la tristeza, el estar callado. Cfr., ARISTÓTELES, Teoría de los colores, Artium, Vitoria, 2006, pp. 132- 133. 
cuerpo acontece de esa nada, en suma, que el gris sólo puede ser comprendido en esta paradoja: como generador de la pintura, y como el más directo y fatídico síntoma de su destrucción.

Después de todo, la etimología del término nos conduce al oscuro vocablo flamenco "grijsen" que, al menos desde principios del siglo XVII, se vinculaba al efecto que lo produce: las lágrimas derramadas en el llanto por los difuntos ${ }^{10}$. Hasta el punto es significativo que la técnica pictórica de la grisalla que contaba con una larga tradición, era conocida como "pintura de colores muertos" en referencia al efecto destructivo del color y al contenido inerte de la piedra a imitar. Así también parece haberlo considerado el propio Delacroix, al menos durante algún tiempo, según reza un apunte de su Journal de 1852 cuando se propone "Penser que l'ennemi de toute peinture est le gris" "1. La máxima no deja de ser una singular advertencia sobre la muerte de la pintura que más tarde, en 1857, convertirá en precepto al desplazar la partícula que indicaba su consideración enunciándolo ahora sin "pensar" y tal y como posteriormente Signac popularizará con admiración en nombre de lo nuevo: "L'ennemi de toute peinture est le gris" advierte ${ }^{12}$. Ahora bien, que exista una enemistad entre gris y pintura indica en el mejor de los casos una falta de pertenencia, una ruptura, una exclusión, incluso. Desde ahora no sólo se pone en evidencia la peligrosidad de su uso, sino el hecho de que no es en sí un color como parece haber comprendido el propio Delacroix al identificarlo en otro momento con la ambigüedad del término "tono local". Sin embargo, Signac emplea este proverbio para justificar los orígenes de su formación anterior a la de su maestro Seurat. De ahí, la necesidad de Delacroix en desterrar los colores terrosos, las "tierras de sombra", decía entonces, que David utilizaba con el pretexto de elaborar todos los colores y contribuir de paso a la reforma del neoclasicismo. Gris, es también sinónimo de Neoclásico. Por ello Eugène Véron quiso recordar que los cuerpos pintados por Ingres o David resultaban a ojos de la

10 vid., COVARRUBIAS, voz “Gris” en Tesoro de la lengua castellana o española, Madrid, 1611, p. 451. "Es un color escura entre pardo y negro [...] dize ser vocablo Aleman, o Flamenco, y trae origen del verbo grijsen, que vale lo mesmo que llorar; porque los que lloran sus difuntos, y se visten de luto traen las ropas desta color, que en Latin se llaman pullas y en Romanece antiguo burieles."

11 DELACROIX, Eugène, op. cit., [ 'sans date, 1852'], p. 316. "Considerar que el enemigo de toda pintura es el gris". Es probable que Delacroix conociera el diccionario de bellas artes de Millin, donde se dedica un artículo al vocablo gris que éste copia a su vez de la Enciclopedia de Watelet y Levesque, y cuya definición se aproxima al pensamiento de Delacroix, al considerar el gris como "un pecado capital del color": "Gris, couleur mêlée de blanc et de noir. Quand le gris est la teinte dominate d'un tableau, il manque d'effet; c'est un vice capital de couleur. Mais les tons gris peuvent être artistement opposés aux tons chauds, vigoureux, et contribuer ainsi á l'heureux ensemble de l'ouvrage". Cfr., MILLIN, Aubin-Louis, voz "Gris" en Dictionnaire des Beaux-Arts, Tome I, Paris, 1806, p. 790.

12 Ibid., [13 de enero de 1857],p. 611.; SIGNAC, Paul D'Eugène Delacroix au neo-impresionnisme, Paris, H. Floury, Librerier-Éditeur, 1911(1899),p.7. Signac se encargará de convertir estas palabras en célebre aforismo de la pintura de Delacroix que empleará en su libro con el pretexto de justificar los orígenes de su formación como antecedente de su maestro Seurat. Partiendo entonces de la fórmula de Delacroix, Signac se dispuso a sistematizar y justificar una pintura que acentuaba con determinación la paradoja de su propósito. Esta enigmática contrariedad de fundar el color en su negación, sobrevive incluso a la II Guerra Mundial al menos hasta el París de postguerra, donde circulaba una leyenda de artista que advertía del excesivo uso del gris en pintura: "un pintor informal que renunció al resto de la pintura por el color, un día antes de suicidarse hizo un cuadro, el último, todo gris, dejando apenas alguna llama amarilla". Cfr., BRUSATIN, Manlio, Historia de los colores, Barcelona, Paidós, 1987, p. 135. 
crítica más esculturas que pinturas, llegando incluso a tildarlos de "flores secas", y a sus pintores de "coloristas grises" según decía un crítico del Salón de 1810, alegando que tal resultado sólo podría explicarse por el uso de esculturas de yeso -y no de carne- como modelo ${ }^{13}$. Sin embargo, el hecho de que Delacroix no pintase a la manera de David pero sí utilizase el gris en su pintura da cuenta de la misma enigmática paradoja colorista que caracterizaba a los pintores antiguos, al pretender lograr el color más espléndido con tintas lúgubres.

Dos son las principales tesis que circulaban sobre el gris en el momento en que Delacroix muestra su interés. En la primera, Des Couleurs Symboliques (1837), Frédéric Portal pretende aleccionar a los artistas desde la premisa del color como modo efectivo de transmisión de ideas, describiendo del blanco al gris la simbología sagrada y profana de cada "color primitivo". Sus observaciones sobre el gris, corroboran que desde el cristianismo es el color del luto pero también el de la "resurrección de la carne". Hasta tal punto que implica la regeneración del hombre nuevo, según el simbolismo sagrado, y de la vida, como ebriedad, según lo profano. El segundo, la famosa De la loi du contraste simultané des couleurs (1839) de Chevreul, delataba su conspiración al aconsejar oscurecer los tonos para obtener un mejor resultado. Se trataba, justamente, de "empobrecer" el color ${ }^{14}$. Por separado no parecen del todo convincentes para Delacroix, en quien se diría encuentran su engarce cuando pinta el cuerpo como acontecer entre el empobrecimiento de la pintura y la resurrección de la carne. Silvestre nos da la clave: la gran preocupación de Delacroix, afirma, consiste en "construir" con masas de color los volúmenes del cuerpo, procediendo "a la manera de un escultor"; como si el sentido del tacto tuviera una especial relevancia en su pintura. Aunque lograr tal efecto corpóreo, dependía del gris: "A l'example du Titien, de Paul Véronèse et Rubens, Delacroix commence par ébaucher son sujet en grisaille, pour arriver simplement et promptement à établir l'éffet general" ${ }^{15}$. Así lo había admitido el propio Delacroix de Veronés, cuando "pone el tono gris vigoroso y transparente que bordea la sombra por el lado del tono gris", y de Rubens que "pone francamente la mediatinta gris del borde de sombra entre su tono local de carne y su frottis transparente" ${ }^{16}$. Este efecto de transparencia del gris exige la concomitancia de lo visual y lo táctil en el encarnado, que Delacroix pudo conocer a través de un célebre enunciado de las reflexiones sobre el arte de Diderot: el "sentimiento de la carne". Con ello trataba de explicar que la complejidad de pintar la carne había cons-

13 VÉRON, Eugène, L'Esthetique, Vol 1, Paris, C. Reinwald, 1878, pp. 295-296.

14 ROQUE, Georges, Art et science de la couleur. Chevreul et les peintres, de Delacroix à l'abstraction, Nimes, Ed. Jacqueline Chambon, 1997, p. 201. "[...] mettre du noir à côté d'une couleur, c'est en abaisser le ton; dans quelques cas, c'est l'appauvrir"; Cfr., PORTAL, Frédéric, "Du Gris", Des Couleurs Symboliques, Paris, 1837, pp. 281-285.

15 SILVESTRE, Théophile (1864), op. cit., "Eugène Delacroix, peintre", p. 50. La misma idea se repite en otras críticas, véase por ejemplo SAINT-VICTOIRE, Paul de, "Le génie de Eugène Delacroix", L'Artiste, 1 novembre, pp. 193-195.

16 DELACROIX, Eugène, op. cit., [3 de noviembre de 1850], p.268; cfr., ibid., [13 de noviembre de 1857], p. 690. "Il est difficile de dire quelles couleurs employaient les Titien et les Rubens pour faire ces tons de chair si brillants et restés tels, et en particulier ces demitintes dans lesquelles la transparence du sang sous la peau se fait sentir malgré le gris que toute demi-teinte comporte. Je suis convaincu pour ma part qu'ils ont mêlé, pour les produire, les couleurs les plus brillantes". 
tituido la desesperación de los grandes coloristas, y Hegel, añadía al respecto en sus cursos de estética de 1826, que esa dificultad residía en lograr pintar la interioridad en la exterioridad de la piel, es decir, en "conseguir la transparencia", dice, que "borra el brillo, y produce ese estar muerto" ${ }^{17}$. Esta misma extrañeza que sólo podía generar el gris, "la mezcla de todos los colores", advierte Hegel, debió sentir Delacroix al vincular el tono local con la pretensión de pintar "la transparencia de la sangre bajo la piel" ${ }^{18}$. El cuerpo es aquí un único color plegado y accesible desde la hechura interna de la piel, como si en efecto su pintura no estuviese hecha sino de sangre y carne. Cuestión fuertemente determinada por su interés por Tiziano. Su Journal de 1857 da cuenta de la lectura del Dialogo della pittura de Lodovico Dolce donde, por cierto, se aconsejaba el color bruno -que en el XVI identificaba al pardo o gris- como el necesario para pintar la carne: "la principal dificultad del colorido reside, pues, en la imitación de las carnes" [...] "los colores que deben imitar la carne tienen algo de pórfido o terroso"; y concluye a este respecto en otra parte: "yo me pronunciaría por un color pardo antes que por uno inconvenientemente blanco [...]. Se lee que el pardo fue usado frecuentemente por Apeles" ${ }^{19}$. Asimismo, Blanc repetía en cierto modo esta idea en L'art dans la parure et dans le vêtement cuando formula cierta pauta con que pintar el encarnado femenino que tanto preocupaba a Delacroix. Esta pauta era el color gris. Una justa cantidad aplicada en la carne permitía anudar vista con tacto gracias a una "ligera capa de polvo" de gris encenizado que al posarse en los cuerpos lograba hacerlos acontecer. Precisamente, "los tonos de la paleta mezclados- escribía Delacroix en 1857- dan un tono de polvo más o menos intenso" proporcionando el efecto de morbidezza que ya advirtiera un año antes en las "medias tintas de la carne" de un cuerpo visto a la intemperie, y que bien debía conocer Blanc, cuando concluye después que el gris "se derrama en la carne" ${ }^{20}$. Pero el causante de este nivel de drama radicalmente "palpable", escribe Blanc, se debía al empleo de aquello que denomina

17 HEGEL, G.W.F., "El color", Filosofia del Arte o Estética (verano de 1826), Madrid, Abada, 2006, pp.443-445. Conviene señalar, como advierten los editores, que la referencia de Hegel sobre esta cuestión no es otra que la Farbenlehre de Goethe.

18 DELACROIX, Eugène, op. cit., ['sans date',1852], p.316. “la teinte locale doit être transparente; quoique demi-teinte, elle imite, dans le principe, la transparence du sang sous la peau”. Paul Mantz ya había advertido esta cuestión en MANTZ, Paul, "Eugène Delacroix", L'Artiste, 15 janvier 1850, p. 82.

19 En la edición castellana del Dialogo della pittura, Santiago Arroyo advierte el vínculo entre el término "bruno"empleado por Dolce, y la célebre técnica de Apeles conocida como atramentum. Vid. DOLCE, Lodovico, Diálogos de la pintura, Madrid, Akal, 2010 (1557), Ed. de Santiago Arroyo Esteban, nota 169, p.208.; Cfr., ibid., pp. 153, 233, 235. En efecto, atramentum [Nat. Hist., XXXV, 50], era un barniz trasparente con base de "nero da calzolaio" que logra luz y equilibrio tonal y geométrico mediante claroscuros [Nat. Hist., XXXIV, 123-25]. Esa oscuridad transparente, el mismo $\mu \varepsilon \lambda o c ̧$ que Plinio atribuye a Apeles [Nat. Hist., XXXV, 50], se extraía de varias formas, señalo especialmente dos: los posos del vino y la combustión de la leña en talleres cerrados para evitar el escape del humo [Nat. Hist. XXXV, 41-42]. Vid., PLINIO SECONDO, Gaio, Storia Naturale, V. Mineralogia e Storia dell'Arte, Libri 33-37, Torino, Einaudi, 1988.

20 Cfr., BLANC, Charles, L 'art dans la parure et dans le vêtement, Paris, 1875, p. 92. "Le blond des cheveux est-il cendré, comme s'il était couvert d'une légère couche de poussière, cette fine poudre semble répandue aussi sur la chair et avoir adouci les yeux et tranquillisé le brillant de la peau. Ainsi chaque tempérament a son harmonie toute faite, ou du moins toute préparée. Il ne s'agit pour l'artiste que de rendre cette harmonie plus suave o plus piquante, de prononcer ce qui demeure indécis, de reveler ce qui est fade, de tempérer ce qui est dur, de donner enfin du relief à ce qui plaira, en rachetant ce qui peut déplaire”.; DELACROIX, Eugéne, op. cit., 7 de septiembre de 1856, p. 591, y 25 de enero de 1857, p. 629. 


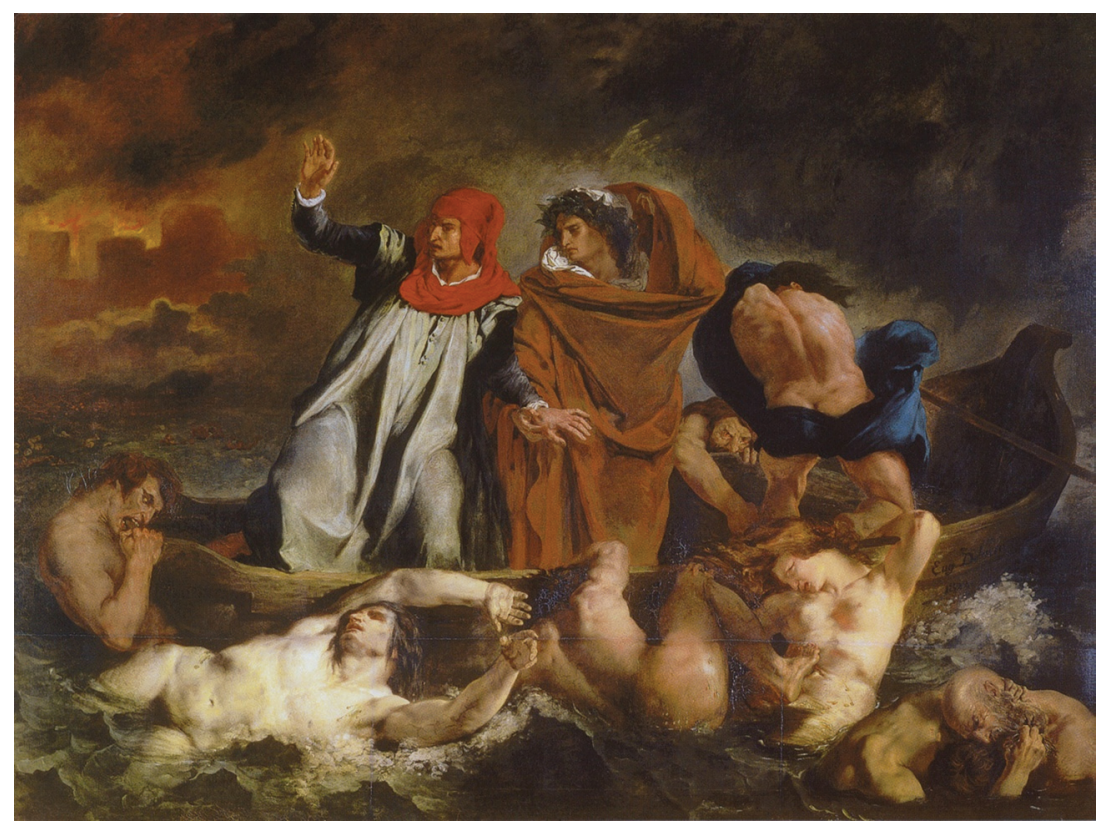

Fig. 2. Eugène Delacroix, La Barque de Dante o Dante et Virgile aux enfers, 1822, óleo sobre lienzo, 189 x 246 cm, Paris (France), Musée du Louvre.

una "armonía lúgubre" del color que subyace como fondo trágico en toda su pintura, y que el propio Delacroix confesaba haber aprendido del singular uso preparatorio de la pintura veneciana que mezclaba rojos con verdes, ocres con tierras ${ }^{21}$. La Barque de Dante (Fig.2) era un ejemplo de este pintar entre el blanco y el negro, señala, y aún antes Baudelaire al calificarla como "auténtica revolución" por lograr con esa tonalidad la mortificación de la carne ${ }^{22}$. Esta idea del gris ocupará una buena parte de su crítica al Salón de 1845. Sobre El Sultán de Marruecos observa que "es tan armonioso pese al esplendor de los tonos, que es gris: gris como la naturaleza, gris como la atmósfera del verano, cuando el sol se extiende como un crepúsculo de polvo tembloroso sobre cada objeto. Por ello no lo percibimos a primera vista. Sus vecinos le oprimen". Y aún un año después, en el Salón de 1846, será el centro de su reflexión en un bello pasaje dedicado al color donde propone el movimiento como condición

21 BLANC, Charles (1876), op.cit., p. 28. "Mais une chose admirable et absolument inattendue alors, c'était la terrible harmonie de couleurs qui recouvrait la composition et la faisait vibrer comme un dramme, ou plutôt cette harmonie lugubre était le fond même de la tragédie”. DELACROIX, Eugène, Journal 18221863, Paris, Plon, 1982, 25 janvier, 1857. "Il reste de Titien des préparations de tableaux, mais dans des sens différents: les unes sont de simples grisalles, les autres sont comme charpentées à grandes touches avec des tons presque cruz; c'était ce qu'il appelait faire le lit de la peinture".

22 BLANC, Charles, Grammaire des arts du dessin, École nationales supérieure des beux-arts, Paris, 2000 (1867), p. 535.; BAUDELAIRE, Charles, "Salón de 1846”, op. cit., p. 113 y ss. "Dante supuestamente vivo, tiene la horrible tez del lugar; Virgilio coronado con un oscuro laurel, tiene los colores de la muerte." 
inherente al gris: "la naturaleza se parece a una peonza que, movida en una acelerada velocidad, nos parece gris, aunque resuma en sí todos los colores". Baudelaire ha debido hacer girar el círculo cromático de Chevreul y caer en la cuenta de la "belleza misteriosa" de lo nuevo, debida en parte al encanto poético del alma pública, esto es, al sentimiento común de desolación de la multitud. Multitud que, a su vez, supone el dominio declarado del pintor de la vida moderna, allí precisamente de donde extrae "lo eterno de lo transitorio", en el placer fugitivo de la circunstancia.

Ahora podemos comprender la complicidad de Delacroix con Blanc en aquel encuentro de 1863, en el que Delacroix venía a confirmar la apreciación del crítico sobre el color local. El sorprendente testimonio con el que Delacroix prosigue parece hasta el momento haber pasado inadvertido, pero tratándose de las palabras de un moribundo merecen la autoridad que la eternidad del hecho mismo le confiere:

"Si le dijera a Veronés: pínteme una bella mujer rubia donde la carne tenga aquel tono [y mostraba con el dedo el sucio gris de la baldosa], obtendrá una bella mujer rubia en su cuadro" 23 .

Delacroix establece aquí el nudo entre gris y carnación en pintura más evidente de lo expuesto hasta ahora, y como tal, llamó poderosamente la atención de Van Gogh que reproduce la anécdota en una carta a su hermano Théo entre 1883 y 1885, donde explica el gris, el "color pobre" como posibilidad de los colores. En este inicio perdido del color encuentra interesante los "grises fríos e incoloros" que Blanc ve en la pintura de Velázquez, los cielos de Corot, el prodigio de los grandes coloristas volviendo grises los rojos más profundos o, la sorprendente facultad de la pintura de lograr "con un sucio y pobre color como el gris del empedrado, pintar un cielo crepuscular o una mujer rubia" ${ }^{24}$. Pues bien, desde 1860 ésta idea ya había despertado un gran interés entre muchos jóvenes pintores holandeses que también descubrieron el gris en la naturaleza. Así fue al menos como un crítico de arte y buen amigo de Zola, J. van Santen Kolff, definía en 1875 las pretensiones de un grupo de artistas que exponían por primera vez en la Academia de dibujo de La Haya. La "Escuela Gris" o la "poesía del gris", como comenzó a conocerse esta pintura realista, consistía en pintar "los efectos de un día gris", decía el crítico, en la tenue atmósfera que rodea no la ciudad sino los campos y playas holandesas más próximas al Mar del Norte, a la manera de aquel poco de nada pintado por Willen Roelofs en el estanque de Nooden.

23 BLANC, Charles (1876), op. cit., p. 24. "voilá un ton, par example (il montrait du doigt le ton gris et sale du pavé); eh bien, si l'on disait à Paul Veronese: peignez-moi une belle femme blonde, dont la chair soit de ce ton-là [gris], il la peindrait, et la femme serait une belle blonde dans son tableau”. Años antes lo advertía de esta manera: "el claroscuro encierra ya una belleza que podría bastar casi a la pintura, pues satisface el relieve de los cuerpos y contiene las poesías del alma”. BLANC, Charles (1867), op.cit., p. 527.

24 GOGH, Vincent van, "Neunen (diciembre de 1883-noviembre de 1885)", Cartas a Théo, Barcelona, Idea Books, 1999, p. 119 y ss. Grises tan distintos como los pintados por Manet en la Rue Mosnier, los tejados de Caillebotte o los que inundan los empedrados de Pisarro entre 1897 y 1898 y que, según Signac, reconstruían "las tintas lúgubres y apagadas del barro de las calles, el hollín de las chimeneas, de los árboles negruzcos, de los techos plomizos y de las muchedumbres mojadas que quería representar en su realidad triste", podrían justificar París como origen de la pintura moderna. Vid., SIGANC, Paul (1899), op. cit., p. 84. 


\begin{abstract}
"Este movimiento -decía van Santen Kolff- trata de reflejar sobre todo el ambiente prefiriendo la terrosidad al color. De aquí su preferencia casi exclusiva por los efectos de un día gris [...]. Los fuertes efectos de luz los trata con desamor, incluso se inclina a renunciar por completo a ellos. A cambio de esto deja al descubierto de un modo desconocido hasta aquí, la poesía del gris. En el ambiente gris encuentra el ideal de la gradación cromática buscada y llenos de admiración hemos de reconocer que con fina sensibilidad intentan reproducir cosas de las que antes se carecía de toda idea. Mauve, Sadée, Israëls, Artz... iqué defensores de la pintura gris!" 25.
\end{abstract}

En efecto, el gris resultaba fundamental por dos motivos. El primero consistía en que lograba el grado máximo de realismo y verdad de lo representado, al tiempo que atenuaba los rojos y generaba mayor vibración en los colores fríos de la paleta. Como el efecto Purkinje, era un cambio en la percepción de la intensidad del color en función del grado de luminosidad atmosférica. El segundo motivo, tenía que ver con esa poética que procedía de las tonalidades grises. Gerard Bilders, uno de los más destacados pintores de esta escuela, lo describió en 1860 como una sensación e incluso como un afecto de la pintura: "el sentimiento de lo gris", escribe ${ }^{26}$. Bilders aseguraba haberlo experimentado con gran intensidad al contemplar la pintura de Corot, Courbet, Dupré o Millet. Y Van Gogh, que había leído con atención sus Cartas y diario, señalaba además las frecuentes quejas, pereza y abatimiento anotadas por el pintor mientras practicaba la pintura; y que esa experiencia pictórica equivalía a "la impresión de un gris vaporoso y cálido" que otros como Maris, Israëls o Haes alcanzarían en la medida en que emprendiesen ese camino que al parecer también había formulado Gigoux y Van Gogh se proponía llevar hasta sus últimas consecuencias. Pero aunque pintar en gris fuera práctica habitual entre "los antiguos", para los críticos holandeses constituía una auténtica amenaza: "Es un pintor peligroso", solían decir de Mauve: "antes Mauve -insistía un crítico en 1863- veía la naturaleza cálidamente y con colores vigorosos, y ahora todo parece envuelto ante sus ojos en un crespón de luto" 27 . En efecto, que un grupo de pintores se inclinase por tonalidades de la melancolía al luto alimentaba la sospecha de una confabulación para acabar con la pintura. “QQué va a ser de la pintura?”, se preguntaba desalentado Van Santen Kolff antes de declarar que esta nueva manera de pintar era decididamente "iconoclasta", teniendo en cuenta que "los grises", dice, prefieren la terrosidad al color. Aunque fijar la atención de la pintura en el lodo de las calles pudiera suponer correr el riesgo de aniquilar el orden pictórico, no tiene en cuenta que a su vez escondía la paradójica pretensión de los antiguos de hacer con ello el color. Como consecuencia, Van Gogh alentaba a los tonalistas a emular a pintores como Millet o Delacroix proponiéndoles el certero uso del gris que denomina "color pobre" porque "realza los colores de la carne". "Si

25 SILLEVIS, John, "La escuela de la Haya" en El joven Van Gogh y la Escuela de la Haya, catálogo de la exposición (Madrid, 1996) Madrid, Sala de las Alhajas, Madrid, 1996, p.18. Así también parecía haberlo comprendido Delacroix años antes de pensar en el gris como enemigo de la pintura, al anotar en su diario que la masa coloreada de cada objeto acontece, escribe, con un "tiempo cubierto, sin sol, sin sombras contrastadas" [...] con "tiempo gris". Vid. DELACROIX, Eugène, op. cit., [ 5 de mayo de 1852], p. 297.

26 SILLEVIS, John, op.cit, p.19.

27 Ibid. 
un día lo quisieran -decía por carta a Théo- podrían hacerlo de la misma manera que Delacroix lo dijo del Veronés, que pinta mujeres desnudas, blancas y rubias, con un color que de por sí se parece mucho al lodo de las calles" ${ }^{28}$.

Sin embargo, no será hasta una década más tarde cuando la obsesión por los monocromos ocupe al escritor y humorista Alphonse Allais en su Album Primo-Avrilesque, publicado en Paris en 1897, el mismo año de clausura del célebre Chat Noir que Allais frecuentaba junto a otros camaradas "hidrópatas" 29 . Seis monocromos del negro al blanco y, entre medias, azul, verde, amarillo, rojo y gris acentuaban la desestabilización visual del orden pictórico, su fragmentación, cuestionando la facultad creativa al pintar complejas obras con un único color. El monocorde gris, Ronde de pochards dans le brouillard [Ronda de borrachos en la niebla] (Fig.3) tocaba además un asunto recurrente entre caricaturistas que Allais recupera en favor de esta fractura: la ebriedad. Émile Duchenne había asumido esta circunstancia en la caricatura que presenta para la Exposition des arts Incohérents (1883) donde Allais expone los monocromos rojo y blanco. Se trataba de un borracho con aspecto desharrapado y triste; era él mismo sentado en la calzada, recuerda Jules Lévy en el catálogo, dibujando con el dedo "j 'ai bu du vin d'Argenteuil; ce vin m'a f...". En otra imagen, la portada del número que La Caricature dedica en 1893 a los "pochards", Steinlen bromeaba con el gris como equívoco entre la atmósfera del mundo moderno y el efecto visual que la embriaguez produce en otro que balbucea: "Sûr que jamais ell'n'voudra croire que j'ai rien bu!" 30 (Fig.3). Ambos casos plantean confusiones próximas al monocromo de Allais que en cambio nos inserta más certeramente en la experiencia de ese efecto visual cuestionando la representación del orden pictórico y nuestra pertenencia al mundo. Y es ahí, donde se ve involucrada la pintura. Porque si Littre define "Pochard" como "un hombre borracho", el vocablo "Pochad" determina un "término de la pintura". Y aclara: es abocetar, difuminar, emborronar con la mano ${ }^{31}$. Allais parece

28 GOGH, Vincent van, op. cit., p. 140.

29 Le Club des Hydropathes fue fundado el 11 de octubre de 1878 y aglutinaba a una serie de escritores, músicos, artistas e intelectuales en torno a la figura del poeta Émile Goudeau: Sarah Bernhardt, Guy de Maupassant, Charles Cros o "el ilustre" Sapeck, caricaturista y pintor a quién Allais había calificado de "el emperador de los fumistas" poco antes de presentar en la exposición de los Incoherentes de 1883 su Mona Lisa fumant la pipe prefigurando a la más conocida de Marcel Duchamp de 1919. Se ha especulado que "hidrópata" [agua $-v \delta \rho o \sigma-\mathrm{y}-\pi \alpha \zeta \iota \alpha-$ afección, dolencia], afección común en el XIX, remite aquí irónicamente al nombre de su fundador Goudeau ['goût d'eau'] y al aborrecimiento que profesaban al agua en oposición al vino, hasta el punto de que Charles Cros solía repetir con insistencia: "Hydropathes, chantons en coeur/La noble chanson des liqueurs".Cf., D'ALIS, Alcé, "Blagues Hydropathesques”, L'Hydropathe, nº1, 1879, p. 4.

30 Vid., La Caricature, 8 de abril, 1893, p. 1. Junto al pochard, dos figuras propias de la Francia moderna derivan del gris: la clase obrera trabajadora y la grisette. La viñeta de un periódico de 1864 ejemplificaba al primer grupo: "Le jour des morts. Un ouvrier descend du cimetière Montmartre, en offensant les murs des deux côtés de la rue. Un de ses camarades le rencontre. -Comment, tu es gris, un jour comme celui-ci, quand il y a six mois que tu as perdu la femme.- Gris!.. Eh bien, après? c'est demi-deuil. ”. Cfr., Le passe-temps. Journal de l'entr'acte, Paris, 1864, p. 2. De este colectivo proviene la "Grisette" como ésta a su vez del gris. La mujer joven y trabajadora, pero también la prostituta, centra toda atención, llegando incluso a fundarse una revista dedicada a ella en exclusividad. Vid., RESCHAL, Antonin, "Notre but", La Grisette, n"1, 1894, p. 1.

31 LITTRÉ, Émile, voz "Pochard", voz "Pochad", en Dictionnaire de la Langue Française, t.III, Paris, L. Hachette, 1874 , p. 1179. Un año después de que viera la luz esta "Ronda de borrachos en la niebla", Allais parece retomar la cuestión en un relato cómico que cuestiona el orden visual tras la ingesta de "vino gris de Ardennes"; en cierto momento el protagonista dice: "Je voulais m'assurer que vous étiez deux, parce que, si 


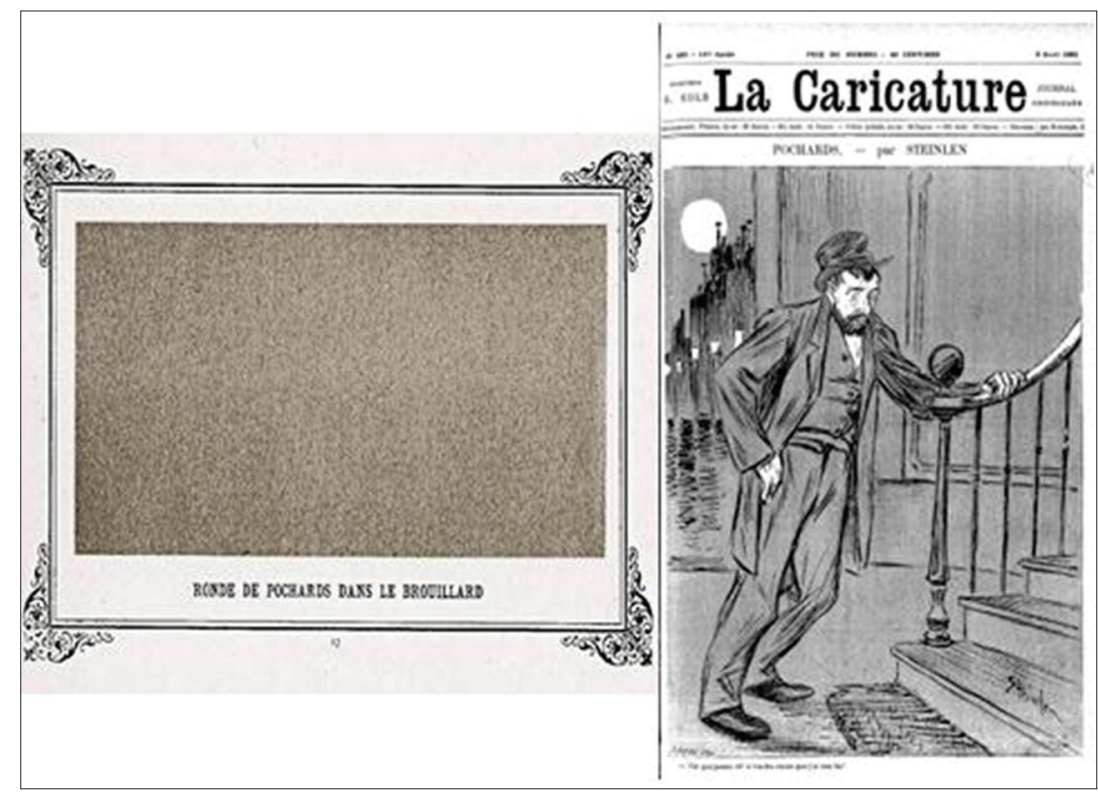

Fig. 3. Alphonse Allais, Ronde de pochards dans le brouillard, 1897, pintura monocroma sobre papel, 25,5x18cm, tomado de ALLAIS, Alphonse, Album Primo-Avrilesque, Paris, $1897, \mathrm{~s} / \mathrm{n}$.

Steinlen, Pochards, tomado de La Caricature, 8 de abril, 1893, p.1.

establecer aquí un juego entre el estado de embriaguez y la ebriedad como fuerza creadora, entrecruzando la referencia a la vista de porchard con el tacto de pochad. En este juego el gris es lo común en ambas expresiones, las articula, pero también desestructura al desencadenar en términos baudelerianos lo "cómico absoluto".

Curiosamente también Delacroix fue acusado de excederse con el gris en la pintura. Y a juzgar por las palabras de Baudelaire al recordar la anécdota, el causante era la misma enigmática visión gris que había tenido Allais: “[...] y le dijo tras muchos cumplidos que era mortificante que un hombre de tan rica imaginación y de tanto talento [...] no quisiera echar un poco de agua en su vino; finalmente le preguntó si no le sería posible modificar su estilo" ${ }^{32}$. ¿Aguar el vino para aclarar la pintura? se habría preguntado Delacroix. ¿O es que acaso pintura y vino poseían tan enigmático y prodigioso efecto de fermentación como el advertido por Cézanne ante las Bodas de Canaá del Veronés al proclamar la transformación del agua en vino y el mundo en pintura?: "Todos esos tonos se nos derraman en la sangre -le decía a Gasquet -[...] nos convertimos en pintura". Con frecuencia en los lienzos del Veronés, prosigue, se

vous n'aviez été qu'un, c'est que j'aurais été, moi, abominablement gris". Cfr. ALLAIS, Alphonse, "L'Homme qui aime a se rendre compte", Amours, délices et orgues, Paris, 1898, pp. 257-261. Cfr. La Caricature, 8 de abril, 1893, p. 1

32 BAUDELAIRE, Charles (1991), op. cit., p. 115. 


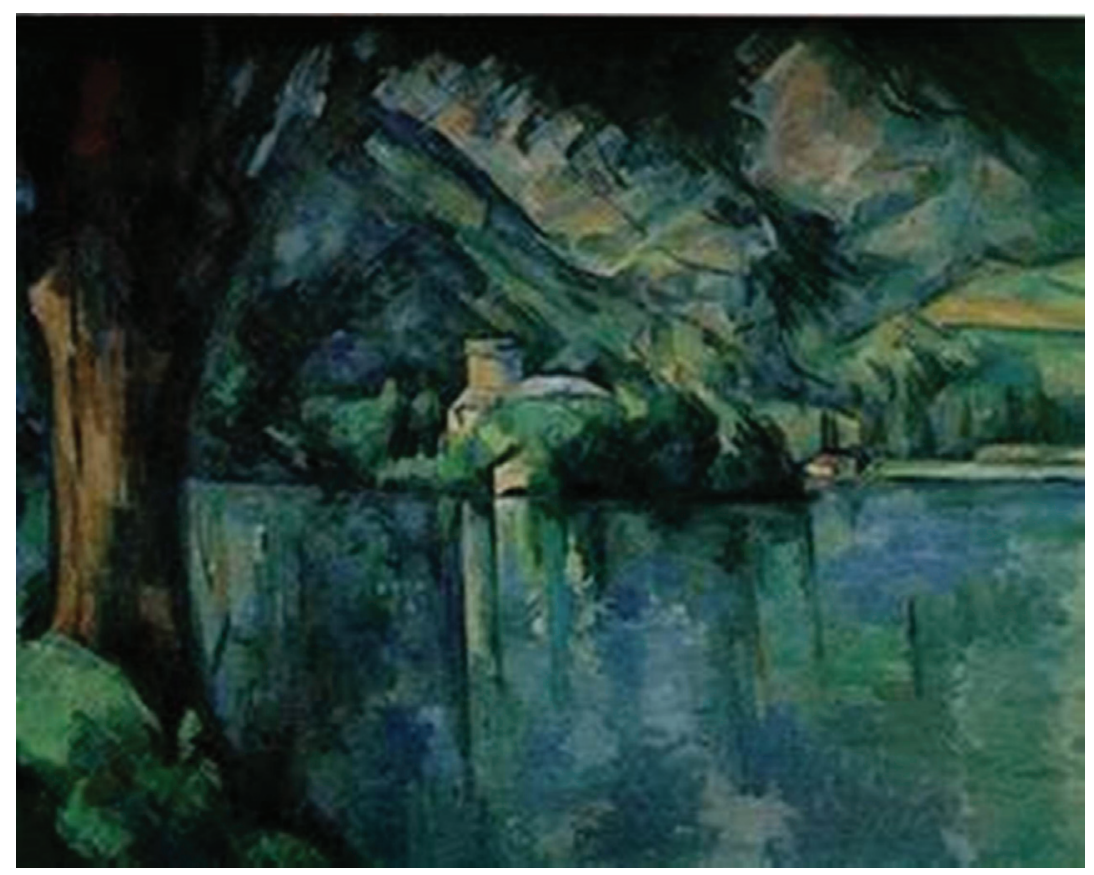

Fig. 4. Paul Cézanne, Le lac bleu o Lac d'Annecy, 1896, óleo sobre lienzo, 65x81cm, London (England), The Courtauld Gallery.

halla "la plenitud de la idea de los colores, la plenitud del pensamiento en el placer" gracias a la insólita manera veneciana de comenzar cubriendo las telas con una "vasta capa de gris" 33 . En el fondo de la tela, el gris, "ebriedad creadora", es para Cézanne la consigna de la pintura; Le lac bleu o Lac d'Annecy de 1896 (Fig.4): "Yo estaba en Talloires. Si buscas un pueblecito de templanzas, ahí tienes uno. ¡Grises, todos los que quieras! Y verdes. Todos los verdes gris del mapa. Las colinas de los alrededores son bastante altas, a mi juicio; parecen bajas iy llueve...! Hay un lago entre dos angosturas, un lago de inglesas. Caen las hojas de los álbumes llenas de árboles a la acuarela. Claro, no deja de ser naturaleza... Aunque distinta a mi manera de verla. ¿Entiendes...? Gris sobre gris. El enemigo de toda pintura es el gris, dice Delacroix. No, nadie será pintor mientras no haya pintado un gris" ${ }^{34}$. Cézanne advierte en el gris

33 GASQUET, Joachim, Cézanne. Lo que vi y lo que me dijo, Madrid, Gadir, 2009, p. 207y ss. Pero, precisa, que si bien en la noche del nacimiento del Salvador las viñas florecieron, "nosotros, los pintores, debemos pintar más bien la floración de esas viñas". Antonio González ha reflexionado lúcidamente sobre este sorprendente enigma de confluencias entre vino y pintura como metáfora de "ebriedad creadora" en GONZÁLEZ RODRÍGUEZ, Antonio Manuel, "En los laberintos de la mente. Iconografía y ritmo de la vid(a) interior”, El cerebro, la gran cepa azul. Arte y Neurociencia, catálogo de exposición (Gran Canaria, 2010) Gran Canaria, Museo Elder de la Ciencia y la Tecnología, 2010, pp.107-162.

34 DORAN, Michael, Sobre Cézanne, Conversaciones y testimonios. Barcelona, Gusavo Gili, 1980, p.161. Para esta cita he optado por la traducción de los escritos recogidos en la editorial Gustavo Gili al considerarla 
un sorprendente intensificador de sensaciones. Ha dado definitivamente con la pintura, con la sensación: tocar, pochad, el acontecer de la pintura. Al fin y al cabo, "sólo esto -le escribía a Pisarro sobre el gris- reina en la naturaleza, pero es algo espantosamente duro de captar" ${ }^{\prime 3}$. Esa dificultad consistía en el riguroso intercambio de acción y pintura, pues "Cézanne -apunta Merleau-Ponty al cabo de los años- no creyó tener que escoger entre sensación y pensamiento, ni tampoco entre caos y orden" ${ }^{36}$ porque esa experiencia se recoge "de golpe" cuando somos dados al mundo desde la pintura. Incluso llega a identificar esta pertenencia con la combustión, y el emerger de la pintura, con los jirones serpenteantes del humo: "quiero adueñarme de esta idea, de este efluvio de emociones, de este humo de ser [...]. El color que asciende [...] de este humo de ser, por encima de la hoguera universal" ${ }^{37}$. Esa hoguera era en verdad el Louvre: "Hay que quemar el Louvre" cuenta Gasquet que le había dicho a Huot en el Salón Carre. Desde luego que sin fuego no hay ceniza. Y que la ceniza confiesa el decurso de un fuego extinguido, pero también lo que resta de aquello que ya no es, de la pintura, y por lo tanto, de la pintura sin presencia e incluso del lugar de la presencia de la pintura que ya no es pintura sino un adueñarse de la sensación. Pero alcanzar todo cuanto de común hay en este proceso de forja del sentido suponía para Merleau "en crevant la peau des choses pour montrer comment les choses se font choses et le monde monde" 38 . Una tarea complicada que el pintor de Aix se había propuesto ante su fascinación por el célebre mantel blanco con panecillos de La Peau de Chagrin de Balzac. Aquel pasaje le hizo comprender que pintar la composición con el empeño de que pareciera un paisaje, eludiendo la naturaleza del objeto, la pintura carecería de la sensación que se había propuesto pintar. Mientras que sólo pintando los objetos en su fascinante modo de aparecer, únicamente posible "en crevant la peau", cabría esperar de aquel trozo de tela con panecillos una "espesura de nieve con coronados" ${ }^{39}$. Del mismo modo que, pienso ahora, si observamos la chaqueta de Cézanne pintada en grises como una tela arrugada y amontonada sobre una silla (Fig.5) tal vez veamos

más aproximada a la idea que Cézanne parece querer señalar a cerca del color gris. El subrayado "Gris sobre gris", es suyo.

35 CÉZANNE, Paul, "Carta de Cézanne a Pisarro , 23 de octubre de 1866”, Correspondencia, La Balsa de la Medusa, Madrid, 1991, p.192.

36 MERLEAU-PONTY, Maurice, "La duda de Cézanne”, Sentido y Sinsentido, Barcelona, Península, 2008, pp. 33-57.

37 GASQUET, Joachim, op. cit., p. 172.

38 MERLEAU-PONTY, Maurice, L'OEil et l'Esprit, Paris, Gallimard, 2008 (1964), p. 69. Walter Benjamin también advierte ese signo inequívoco en la obra de arte al afirmar que las manifestaciones artísticas en torno a 1935 trataban de "acercar humanamente las cosas" [...] de "quitarle su envoltura a cada objeto, triturar su aura". Cfr., BENJAMIN, Walter, "La obra de arte en la época de su reproductibilidad técnica", Discursos Interrumpidos I, Madrid, Taurus, 1973, p. 25.

39 MERLEAU-PONTY, Maurice, (1991), op. cit., p. 43. Conviene recordar que "la piel de zapa", gruesa y áspera parecida a una "plancha metálica", decía Balzac, por la rigidez y el color gris plateado, reunía a un tiempo la voluptuosidad del placer y del dolor, pues por cada deseo mágicamente concedido a quien de ella hacía uso, reducía considerablemente sus dimensiones. Pero en el XIX, chagrin definía también el mismo estado de ánimo con el que Balzac presenta a su protagonista Raphaël Valentin y que a lo largo de la centuria acabaría identificando al gris: la piel del triste, diríamos entonces, del pensativo, reservado, aburrido o melancólico. Cfr., LITTRÉ, Émile, (1874), voz “Chagrin”, t.I, op. cit., pp. 536-537. 


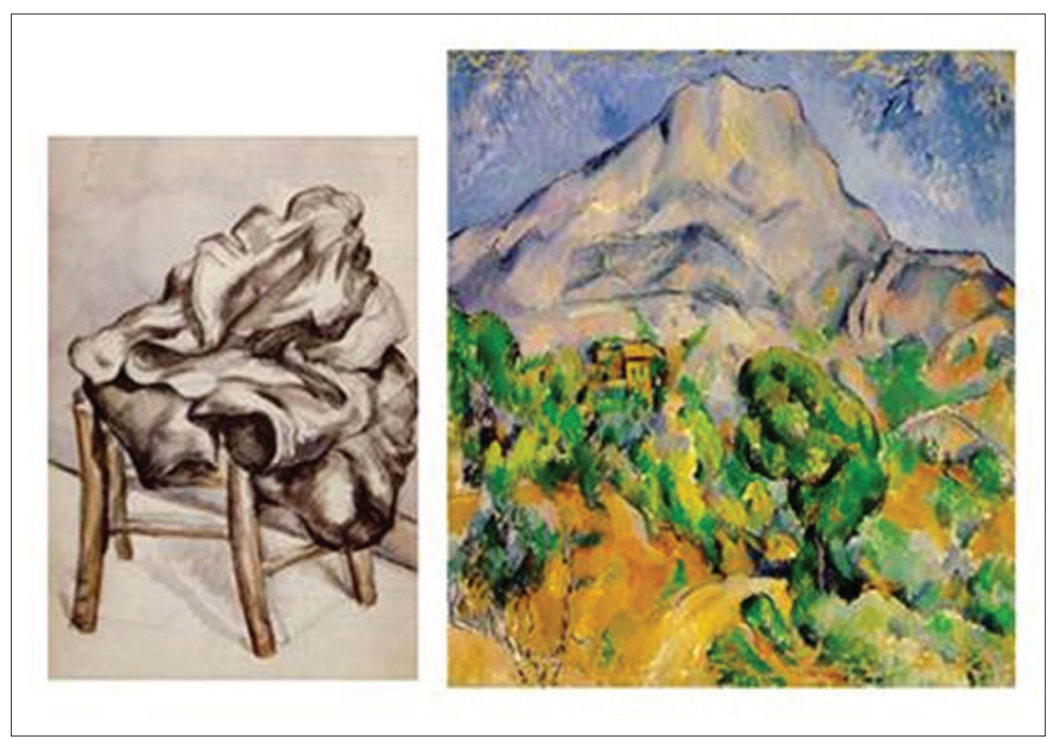

Fig. 5. Paul Cézanne, Mont Sainte-Victoire, 1896-1898, óleo sobre lienzo, 78x99cm, St. Petersburg (Russia), The State Hermitage Museum. Paul Cézanne, Veste sur une chaise, 189092, acuarela y grafito sobre papel, 47,5 x 30,5 cm., Marianne Feilchenfeldt, Zurich.

emerger los mismos quiebros y derroteros de la montaña Saint-Victoire que Cézanne había pintado y recorrido como caminante con esa misma piel, la piel de lo moderno.

Durante esos años Lipps comenzó a advertir una acusada ausencia de sensación como fenómeno distintivo del mundo moderno ${ }^{40}$. Un testimonio que Walter Benjamin tendría en cuenta al reflexionar sobre cómo esa carencia se había acentuado a través de una dualidad desgarradora en su texto Experiencia y Pobreza. Lo uno es reverso de lo otro. La pobreza, de la abundancia de propuestas espirituales -Benjamin habla de espiritismo o quiromancia- desplazadas por la necesidad de su reverso; el de la experiencia, la propia pérdida de la laboriosidad que implica toda narración: su pobreza. Esta pobreza de experiencia, dice en otra parte, es como "un paño cálido y gris forrado por dentro con la seda más ardiente y coloreada. En este paño nos envolvemos al soñar. En los arabescos de su forro nos encontramos entonces en casa. Pero el durmiente tiene bajo todo ello una apariencia gris y aburrida. Y cuando luego despierta y quiere contar lo que soñó, apenas consigue sino comunicar este aburrimiento. Pues ¿quién podría volver hacia afuera, de un golpe, el forro del tiempo?" ${ }^{41}$. Con este interrogante Benjamin formula una dificultad clave respecto al gris: ¿cómo generar experiencia si somos pobres de experiencia? La distancia era grande, pero cuestionar el principio de historia podía ser la solución. En el salto entre el "aquí" de

40 Vid., LIPPS, Théodor, "Überdie Symbolik unserer Kleidung”, Nord und Süd, XXXIII, Bresleau/Berlin, 1885, p. 352, en BENJAMIN, Walter, Libro de los pasajes, Madrid, Akal, 2004, p. 107.

41 BENJAMIN, Walter, [D 2 a, 1], 2004, p. 130. 
la pobreza de experiencia y el "allí" de una experiencia pasada, se da lo que Benjamin llama imagen dialéctica, es decir, la constelación o vínculo que los une en un relámpago que nos atormenta y persigue, que nos despierta. Así, despertamos, quizás, como despierta de golpe el durmiente cuando ve interrumpido su sueño. Y es justo en esta interrupción donde nos adueñamos de la imagen que articula esa experiencia, el sentido, la sensación de lo que ha sido con lo que ahora es. Eliminar la distancia entre las cosas o, más exactamente, aproximarlas a nosotros mismos desde lo más remoto, se presentaba como un inequívoco signo de progreso. Éste evidencia a su vez un temblor constante en Benjamin que acuña su célebre el calor se está yendo de las cosas con el que procura el cambio de paradigma perceptivo desplazando, subrepticiamente, la vista por el tacto: "las tareas que en las épocas de cambio se le plantean al aparato perceptor humano no cabe en absoluto resolverlas por la vía de la mera óptica, es decir, de la contemplación. Poco a poco irán siendo cumplidas, bajo la guía de la recepción táctil, por la repetición y la costumbre"42.

Esta exigencia vertebra la idea según la cual Benjamin comprende aquella doble condición de reverso que determina la confluencia de gris y tacto. A pesar de que en 1931 Berlín no contaba con un mapa militar, un mapa de destrucción, pues se desconocía aún "el escenario de la guerra futura", Benjamin proyectó un mapa "gris" de Berlín en el que situar los recuerdos de su más temprana vida en la capital alemana. Sobre el plomizo fondo del plano-guía de su Berlin vécu, Benjamin identifica mediante el espectro de colores, las casas de sus amigos, los lugares de conversación y reunión de las juventudes comunistas, hoteles, cafés desaparecidos, burdeles frecuentados, el camino a la escuela...Con cada imagen callejera pretendía recobrar, cual Proust, "cada sensación táctil por las que hemos abierto todo esto", aunque lo esencial de esas imágenes desdobladas y superpuestas por la acción del recuerdo que Benjamin equipara a un abanico, se encuentre en el pliegue que las sobrepone -el presente con el pasado- y que en efecto como un abanico siempre está por abrir y descubrir ${ }^{43}$.

Gris debe por tanto ser entendido en términos positivos, de igual modo que Benjamin daba cuenta en Experiencia y Pobreza de este estado fundamental de la sensa-

42 BENJAMIN, Walter, "La obra de arte en la época de su reproductibilidad técnica", Obras, Libro I, vol. 2, Madrid, Abada, 2008, p. 82.

43 BENAJMIN, Walter, "Crónica de Berlín” (1931), Personajes alemanes, Barcelona, Paidós, 1995, pp. 23-24. Esta Berlin vécu recuerda dos huellas importantes en Benjamin. Por un lado, al singular fotomontaje de Sasha Stone para la portada de Dirección Única de 1928. Se trata de la fotografía en blanco y negro de una calle de Berlín en la cual varias señales superpuestas en forma de flecha obligan al ojo a recorrerla en abanico, pues éstas se suceden enmarcando en rojo la palabra "Einbahnstraße", calle de dirección única, con la que parecen indicar con urgencia, de un extremo a otro de la fotografía, el límite de apertura del libro. Una constelación de aperturas de sentido -sin duda- si consideramos cada uno de sus epígrafes, distintos remitentes unidos entre sí como relámpagos de sensaciones táctiles. Sobre el "sentido" de Dirección Única véase la interesante reflexión de LESMES GONZÁLEZ, Daniel, "Destino por determinar: sobre Dirección Única de Walter Benjamin”, BAJO PALABRA. Revista de Filosofia, II Época, No 3, 2008, pp. 13-24. Por otro lado, teniendo en cuenta el interés de Benjamin por Goethe, cabría relacionar su Berlin vécu con el mapa concebido por el poeta y Marianne von Wellmer la noche del 18 de octubre de 1814, en lo alto de una torre cercana al Gerbermühle de Frankfurt. Se cuenta que sobre un mapa de la ciudad situaban puntos rojos a medida que se encendían los fuegos fatuos por la celebración de la victoria sobre las tropas napoleónicas en la batalla de Leipzieg, y que al día siguiente, Goethe, lo llevaría consigo a Weimar. 
ción con el vocablo "barbarie". Ambos implican todo comienzo como tarea primera de la construcción, como principio que dicta tabula rasa en la mesa del dibujante. Paul Klee era en este sentido un buen ejemplo de constructor. Su precisión simbólica llamó de inmediato la atención de Benjamin que adquiere su famosa acuarela $\mathrm{An}$ gelus Novus. Pero la presentación de este principio, presupone el caos como noción paradójicamente localizada y como pieza clave en la conformación de la pintura, explica Klee en su texto Nota sobre el punto gris. Este punto es una interrupción. Es el fatídico cruce de caminos del color que el artista entiende como origen enigmático, como caos absoluto de ser, confusamente, nada entre "lo que deviene y lo que muere" ${ }^{44}$. Aquí, Deleuze ha distinguido dos tipos de gris. Uno procedente del blanco/ negro (caos). El otro, muy particular, indisociablemente ligado al primero: el verde/ rojo. Comienza por situar el punto gris de partida en el caos, en razón de conceder a la creación una concentración originaria desde donde las cosas se hacen mundo. Pero el gris no puede estar localizado, es de nuevo la paradoja del colorista que salta por encima de sí, encarnando "el acto de pintar" ${ }^{45}$. Éste guarda en la catástrofe la precariedad extrema de una generación artística, entre 1914 y 1918, cuya tarea se vería atravesada por el impetuoso reclamo del sentido ${ }^{46}$. Y parece que es ese pliegue del sentir la exigencia que el gris proclama en virtud de su pertenencia al arte, un arte que cabría ser denominado pobre y hasta de los pobres. A fin de cuentas, el hombre contemporáneo no añoraba la novedad de experiencia sino la liberación de aquella dramática que había padecido. Lo decisivo estaba en las huellas que traían a la memoria la experiencia física del mundo y que el sentido del tacto en clave de categoría estética atesoraba. "Nos hemos hecho pobres", concluye Benjamin.

No se puede pasar por alto este nuevo concepto de gris, donde el tacto como aparato perceptivo recobrado resulta indispensable, pues la dimensión constructiva de la pintura requiere de esta compleja articulación. Klee lo analiza retomando el aforismo de Cézanne con el que damos título y comienzo a este artículo, y cuyo sentido invierte aunque no así su propósito: centrar de nuevo el origen en un centro sin centro. Con todo, niega ser "gris sobre gris", afirma, pues de lo contrario ¿acaso no acabaríamos con la pintura? He aquí, una vez más, la contrariedad de los grandes coloristas con la que nos es devuelta la mirada a las infinitas posibilidades de lo nuevo. Pero este intrincado comienzo requiere de la mano como torrente de acción en el acto constructivo de pintar. Cada movimiento, un instante entre instantes, un parpadeo, una apertura que se sostiene en esta suerte de aire tenebroso: justo ahí, donde la pintura siempre está por venir.

44 KLEE, Paul, Teoría del arte moderno, Buenos Aires, Cactus, 2007, p. 55.

45 passim DELEUZE, Gilles, Pintura: el concepto de diagrama, Buenos Aires, Cactus, 2007. El gris como "catástrofe-germen", como "caos" absoluto y, más exactamente, como "chaosmos" - concepto que el propio Deleuze asumirá de Finnegans Wake de Joyce para su Diferencia y repetición (1968) y que años antes ya había sido señalado en el mismo sentido por Umberto Eco en Opera aperta (1962)- corresponde para Deleuze a la "potencia de la mano del pintor" una vez ésta liberada de la tradicional jerarquía que el esquema visual ha venido imponiéndose en las artes a lo largo de toda la cultura occidental.

46 BENJAMIN, Walter, "Experiencia y pobreza", Discursos interrumpidos I, Madrid, Taurus, 1973 , pp. $165-174$ 